\title{
Diagnosis and Treatment of Incident Hypertension Among Patients with Diabetes: a U.S. Multi-Disciplinary Group Practice Observational Study
}

\author{
Margaret L. Wallace, PharmD MS ${ }^{7}$, Elizabeth M. Magnan, MD' , Carolyn T. Thorpe, PhD MPH? , \\ Jessica R. Schumacher, $P^{2} D^{3,4}$, Maureen A. Smith, MD PhD MPH ${ }^{1,3,4,5}$, and Heather M. Johnson, MD MS 1,6 \\ 'Department of Family Medicine, University of Wisconsin School of Medicine and Public Health, Madison, WI, USA; ${ }^{2}$ Center for Health Equity \\ Research and Promotion, Veterans Affairs Pittsburgh Healthcare System and Department of Pharmacy \& Therapeutics, School of Pharmacy, \\ University of Pittsburgh, Pittsburgh, PA, USA; ${ }^{3}$ Health Innovation Program, University of Wisconsin School of Medicine and Public Health, Madison, WI, \\ USA; ${ }^{4}$ Department of Surgery, University of Wisconsin School of Medicine and Public Health, Madison, WI, USA; ${ }^{5}$ Department of Population Health \\ Sciences, University of Wisconsin School of Medicine and Public Health, Madison, WI, USA; ${ }^{6}$ Department of Medicine, Division of Cardiovascular \\ Medicine, University of Wisconsin School of Medicine and Public Health, Madison, WI, USA.
}

BACKGROUND: Early hypertension control reduces the risk of cardiovascular complications among patients with diabetes mellitus. There is a need to improve hypertension management among patients with diabetes mellitus.

OBJECTIVE: We aimed to evaluate rates and associations of hypertension diagnosis and treatment among patients with diabetes mellitus and incident hypertension.

DESIGN: This was a 4-year retrospective analysis of electronic health records.

PARTICIPANTS: Adults $\geq 18$ years old ( $n=771$ ) with diabetes mellitus, who met criteria for incident hypertension and received primary care at a large, Midwestern academic group practice from 2008 to 2011 were included

MAIN MEASURES: Cut-points of 130/80 and 140/ $90 \mathrm{mmHg}$ were used to identify incident cases of hypertension. Kaplan-Meier analysis estimated the probability of receiving: 1) an initial hypertension diagnosis and 2) antihypertensive medication at specific time points. Cox proportional-hazard frailty models (HR; $95 \% \mathrm{CI}$ ) were fit to identify associations of time to hypertension diagnosis and treatment.

KEY RESULTS: Among patients with diabetes mellitus who met clinical criteria for hypertension, $41 \%$ received a diagnosis and $37 \%$ received medication using the 130/ $80 \mathrm{mmHg}$ cut-point. At the 140/90 mmHg cut-point, $52 \%$ received a diagnosis and $49 \%$ received medication. Atrial fibrillation (HR 2.18; 1.21-4.67) was associated with faster diagnosis rates; peripheral vascular disease (HR $0.18 ; 0.04-0.74$ ) and fewer primary care visits (HR 0.93; 0.88-0.98) were associated with slower diagnosis rates. Atrial fibrillation (HR 3.07; 1.39-6.74) and ischemic heart disease/congestive heart failure (HR 2.16; 1.24-3.76) were associated with faster treatment rates; peripheral vascular disease (HR 0.16; 0.04-0.64) and fewer visits (HR 0.93; 0.88-0.98) predicted slower medication initiation. Diagnosis and treatment of incident hypertension were similar using cut-points of 130/80 and 140/90 mmHg.

CONCLUSIONS: Among patients with diabetes mellitus, even using a cut-point of 140/90 mmHg, approximately $50 \%$ remained undiagnosed and untreated for hypertension. Future interventions should target patients with multiple comorbidities to improve hypertension and diabetes clinical care.

Published online February 4, 2015
KEY WORDS: hypertension; diabetes mellitus; diagnosis; electronic health records.

J Gen Intern Med 30(6):768-76

DOI: $10.1007 / \mathrm{s} 11606-015-3202-0$

(C) Society of General Internal Medicine 2015

\section{INTRODUCTION}

Macrovascular and microvascular complications are major causes of morbidity and mortality in patients with diabetes mellitus. ${ }^{1}$ Hypertension is common in patients with diabetes mellitus and is a risk factor for accelerating the progression of such complications. ${ }^{2}$ Blood pressure control following the onset of hypertension in patients with diabetes is associated with lower rates of microvascular complications ${ }^{1,2}$; blood pressure control within 6 months is associated with a significant decrease in major cardiovascular events. ${ }^{2}$ This underscores the importance of early recognition and timely hypertension control in patients with diabetes. Despite the importance of controlling blood pressure in patients with diabetes mellitus, there is evidence that blood pressure control is suboptimal among U.S. patients with diabetes. $^{2,3}$

A better understanding of factors associated with delays in diagnosis and treatment of hypertension among patients with diabetes could inform the development of interventions to improve the clinical care of diabetes. We therefore aimed to identify associations with an initial hypertension diagnosis and antihypertensive medication initiation among individuals with diabetes mellitus.

\section{METHODS}

\section{Sample}

This study was approved by the University of WisconsinMadison Health Sciences Institutional Review Board with a waiver of consent. This secondary retrospective cohort analysis used electronic health record data from a large, 
Midwestern, multi-disciplinary academic group practice. To construct the sample (Fig. 1), we identified all patients $\geq 18$ years old who met criteria from the Wisconsin Collaborative for Healthcare Quality (WCHQ) 4,5 for being "currently managed" in the healthcare system between 1 January 2008 and 31 December 2011. Per WCHQ criteria, patients had to have $\geq 2$ billable office encounters in an outpatient, nonurgent, primary care setting, or one primary care and one office encounter in an urgent care setting, in the 3 years prior to study enrollment, with at least one visit in the prior 2 years. ${ }^{6}$ Electronic health records were assessed for the date a patient met the Seventh Report of the Joint National Committee on Prevention, Detection, Evaluation, and Treatment of High Blood Pressure (JNC 7) clinical blood pressure criteria for a new diagnosis of hypertension ${ }^{7}$ (incident hypertension) without receiving a previous diagnosis or treatment for hypertension. JNC 7 criteria were the established U.S. hypertension guidelines during the reporting period. A patient met blood pressure eligibility criteria based on electronic health record data if: a) $\geq 3$ outpatient blood pressure measurements from three separate dates, $\geq$ 30 days apart, but within a two-year span, were elevated (systolic blood pressure $\geq 130 \mathrm{mmHg}$ or diastolic blood pressure $\geq 80 \mathrm{mmHg}$ ) according to JNC 7 criteria; or b) there were two elevated blood pressures ${ }^{8,9}$ (systolic blood pressure $\geq 160 \mathrm{mmHg}$ or diastolic blood pressure $\geq 100 \mathrm{mmHg}$ ), $\geq 30$ days apart within a 2-year period. If more than one blood pressure was taken at a visit, the average was used. ${ }^{10}$ Hospital and emergency department blood pressures were excluded.

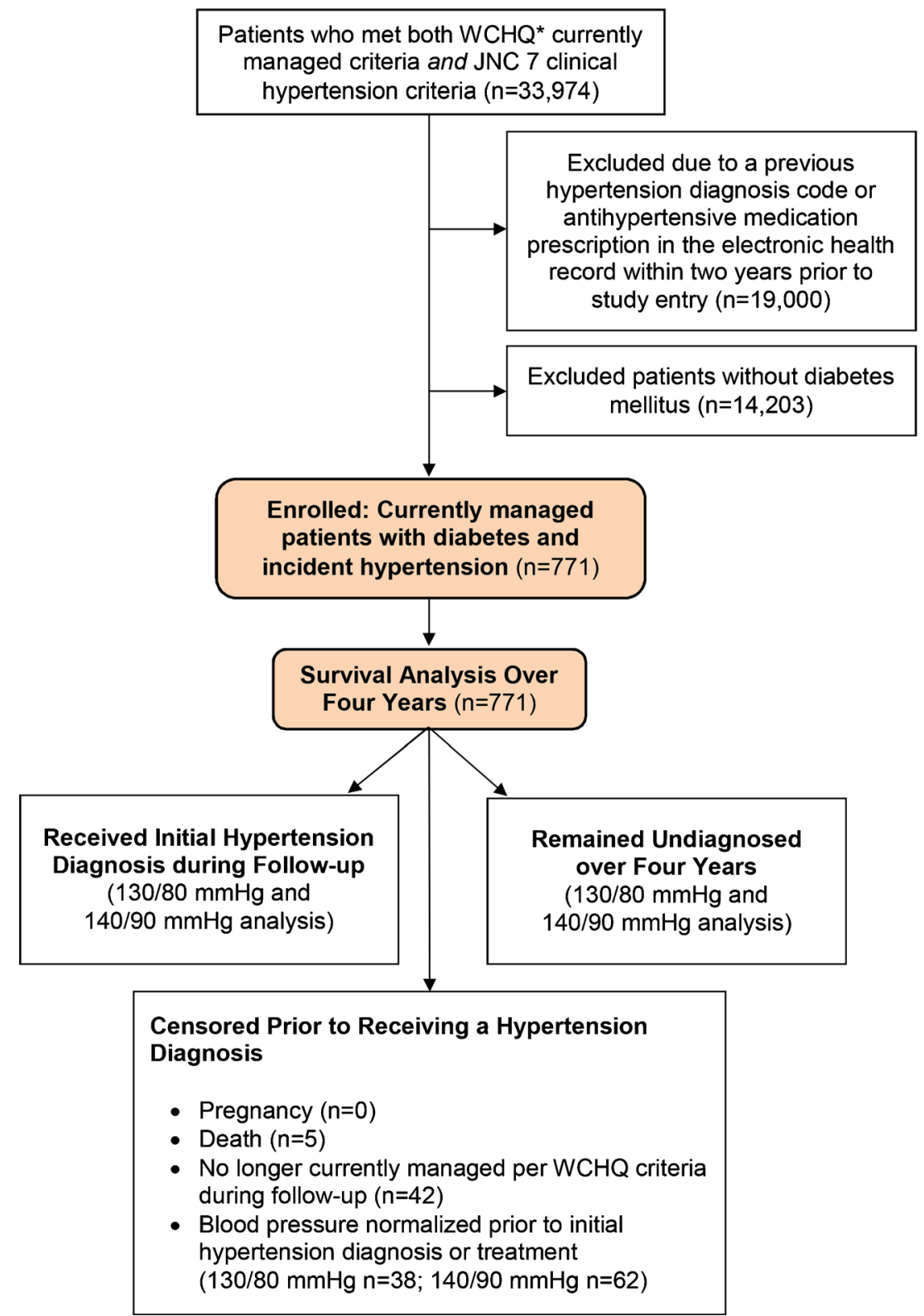

Figure 1 Study sample: enrollment and analysis. *WCHQ: Wisconsin Collaborative for Healthcare Quality. 
Each patient meeting blood pressure eligibility and currently managed criteria received an "index date" (the first date both criteria were met). A 365-day period prior to this index date was the "baseline period" to assess patients" comorbidities and healthcare utilization. Patients were included if they met Hebert's criteria for a diabetes mellitus diagnosis in the baseline period (ICD-9 codes: 250.00-250.93 [diabetes and complications], 357.2 [polyneuropathy in diabetes], 362.0362.02 [diabetic retinopathy], 366.41 [diabetic cataract]). ${ }^{11}$ All of the patients were diagnosed with diabetes by screening lab tests. Screening methodologies for diabetes (e.g., HgbA1C, fasting plasma glucose, etc.) within this healthcare system have been previously published. ${ }^{12}$ Patients continued to accrue time in the study from the index date until they achieved study outcomes (hypertension diagnosis and/or antihypertensive medication initiation), censoring, or the study ended. Patients were censored if they died (censored day of death; $0.6 \%$ ), were no longer currently managed (censored at the end of the calendar year; $5.4 \%$ ), or achieved hypertension control prior to diagnosis or treatment, defined as three consecutive normal blood pressures on three separate dates (130/ $80 \mathrm{mmHg} 5.2 \%$ [ $n=38] ; 140 / 90 \mathrm{mmHg} 8.1 \%[n=62])$.

Prior to enrollment, patients were excluded if they had a previous diagnosis of hypertension based on Tu's ICD-9 criteria (401.x [essential hypertension], 402.x [hypertensive heart disease], 403.x [hypertensive renal disease], 404.x

Table 1 Baseline Demographics*

\begin{tabular}{|c|c|c|c|}
\hline & Total population $n=771$ & $\begin{array}{l}\text { Received hypertension } \\
\text { diagnosis } n=315\end{array}$ & $\begin{array}{l}\text { Received antihypertensive } \\
\text { medication } n=286\end{array}$ \\
\hline \multicolumn{4}{|l|}{ Patient characteristics } \\
\hline Age, $m(S D)$ & $54(14)$ & $56(14)$ & $56(14)$ \\
\hline Female & $396(51)$ & $153(49)$ & $130(45)$ \\
\hline \multicolumn{4}{|l|}{ Race/ethnicity } \\
\hline White & $643(83)$ & $260(83)$ & $235(82)$ \\
\hline Non-white ${ }^{\dagger}$ & $128(17)$ & $55(17)$ & $51(18)$ \\
\hline \multicolumn{4}{|l|}{ Marital status } \\
\hline Married/Partnered & $440(57)$ & $186(59)$ & $179(63)$ \\
\hline Unmarried & $331(43)$ & $129(41)$ & $107(37)$ \\
\hline Medicaid, ever & $110(14)$ & $43(14)$ & $40(14)$ \\
\hline \multicolumn{4}{|l|}{ Tobacco use category } \\
\hline Current tobacco use & $349(45)$ & $143(45)$ & $133(47)$ \\
\hline Non-smoker/former tobacco use & $422(55)$ & $172(55)$ & $153(54)$ \\
\hline Body mass index, $\mathrm{kg} / \mathrm{m}^{2}, m(S D)$ & $34(8.3)$ & $34(8.0)$ & $34(8.5)$ \\
\hline \multicolumn{4}{|l|}{ Primary spoken language } \\
\hline English & $712(92)$ & $299(95)$ & $273(95)$ \\
\hline Other & $59(7.7)$ & $16(5.1)$ & $13(4.6)$ \\
\hline \multicolumn{4}{|l|}{ Stage of hypertension ${ }^{\S}$} \\
\hline Stage 1 & $639(83)$ & $245(78)$ & $224(78)$ \\
\hline Stage 2 & $132(17)$ & $70(22)$ & $62(22)$ \\
\hline \multicolumn{4}{|l|}{ Comorbidities } \\
\hline Microvascular complications of diabetes" & $49(6.4)$ & $17(5.4)$ & $16(5.6)$ \\
\hline Baseline dyslipidemia & $377(49)$ & $154(49)$ & $141(49)$ \\
\hline Atrial fibrillation & $11(1.4)$ & $6(1.9)$ & $7(2.5)$ \\
\hline Cerebrovascular disease with or without complications & $19(2.5)$ & $5(1.6)$ & $6(2.1)$ \\
\hline Peripheral vascular disease & $31(4.0)$ & $7(2.2)$ & $6(2.1)$ \\
\hline Depression & $75(9.7)$ & $26(8.3)$ & $28(9.8)$ \\
\hline Ischemic heart disease ${ }^{\#}$ & $31(4.0)$ & $14(4.4)$ & $16(5.6)$ \\
\hline Low prevalence indicator ${ }^{* *}$ & $52(6.7)$ & $16(5.1)$ & $19(6.6)$ \\
\hline \multicolumn{4}{|l|}{ Baseline ambulatory visit counts, annual, $m(S D)$} \\
\hline Primary care visits & $3.6(3.1)$ & $3.1(2.5)$ & $3.1(2.6)$ \\
\hline Specialty care visits & $2.8(3.3)$ & $2.3(2.8)$ & $2.2(3.0)$ \\
\hline Urgent care visits & $0.53(1.1)$ & $0.39(0.89)$ & $0.35(0.82)$ \\
\hline \multicolumn{4}{|l|}{ Provider characteristics ${ }^{\dagger \dagger}$} \\
\hline Female & $337(44)$ & $143(45)$ & $125(44)$ \\
\hline \multicolumn{4}{|l|}{ Specialty providing majority of ambulatory care } \\
\hline Internal medicine & $318(41)$ & $131(42)$ & $114(40)$ \\
\hline Family medicine & $375(49)$ & $154(49)$ & $141(49)$ \\
\hline Other & $78(10)$ & $30(9.5)$ & $31(11)$ \\
\hline Age, $m(S D)$ & 47 (10) & $46(10)$ & $46(10)$ \\
\hline
\end{tabular}

*Values represent numerators and percents unless otherwise specified. Diagnosis and treatment is based on 130/80 mmHg threshold

${ }^{\dagger}$ Non-white ethnicities: African American (8.0\%); Hispanic/Latino (3.1\%); Asian (2.0\%); Native Hawaiian/Pacific Islander (0.9\%); American Indian/ Alaska Native (0.1\%); Unknown (2.5\%)

* On Medicaid during the baseline or study period

${ }^{\S}$ Stage of hypertension is defined using JNC-7 criteria

"An indicator variable was created for microvascular disease that consists of the presence of chronic kidney disease and/or eye disease

"An indicator variable was created for cerebrovascular disease for the presence of any of the following co-morbidities: stroke, transient ischemic attack, or other neurologic condition

${ }^{\#}$ An indicator variable was created for ischemic heart disease that consists of the presence of congestive heart failure and/or ischemic heart disease

${ }^{* *}$ Due to low prevalence, an indicator variable was created for the presence of any of the following comorbidities: dementia, collagen vascular disease, malignancy

${ }^{\dagger}$ AMA is the source for the raw physician data (provider ages only); statistics, tables or tabulations were prepared by User-Customer (PI: H. Johnson) using AMA Masterfile data

Hther specialties: Pediatrics; obstetrics/gynecology; geriatrics 
[hypertensive heart and renal disease], 405.x [secondary hypertension]), ${ }^{13}$ or had an antihypertensive prescription in the electronic health record. Patients who were pregnant during the study were excluded 1 year before, during, and 1 year following pregnancy using a modified Manson approach $(0 \%){ }^{14}$ The final sample was 771 currently managed patients with diabetes and incident hypertension (Fig. 1).

\section{Primary Outcome Variables}

This study evaluated two primary outcomes: 1) time (days) from index date to the initial hypertension diagnosis, and 2) time (days) from enrollment to antihypertensive medication initiation. Days to diagnosis and treatment were converted into months. During the study period, 130/80 $\mathrm{mmHg}$ was the hypertension diagnosis and treatment threshold for patients with diabetes (JNC 7). ${ }^{7}$ However, our analysis also included $140 / 90 \mathrm{mmHg}$ to reflect clinical trials and guideline updates. ${ }^{1,15,16} \mathrm{An}$ initial hypertension diagnosis was defined as the date of the first outpatient electronic health record documentation of an ICD-9 code for hypertension per the Tu criteria $^{13}$ or ICD-9 code 796.2 ("elevated blood pressure without a diagnosis of hypertension"). ${ }^{17}$ Medication initiation was defined by the first outpatient electronic health record documentation of an antihypertensive prescription as defined by Multum Lexicon ${ }^{\mathrm{TM}}$ Plus (Cerner Multum, Inc., Denver, CO), a database of all prescription and drug products in the U.S.

\section{Explanatory Variables}

The selection of explanatory variables was guided by the concept of clinical inertia (delays in diagnosis and treatment). ${ }^{18-20}$ According to previous studies, competing comorbidities, in addition to multiple patient, healthcare system, and provider factors, contribute to clinical inertia. ${ }^{19,21}$ Baseline patient-related variables included: age, gender, marital status, race/ethnicity, tobacco use, socioeconomic status (defined as ever having Medicaid), body mass index, and severity of blood pressure elevation at study entry (categorized as 130 $159 / 80-99 \mathrm{mmHg}$ or $\geq 160 / 100 \mathrm{mmHg}$ ). Patient comorbidities were defined with ICD-9 codes using validated algorithms. The Centers for Medicare and Medicaid Services' Chronic Condition Warehouse algorithm was used to identify ischemic heart disease. ${ }^{22}$ An established algorithm was used to identify stroke/transient ischemic attack. ${ }^{23}$ Elixhauser algorithms ${ }^{24}$ were utilized to identify depression, other neurologic disorders, collagen vascular disease, and solid tumors (without metastasis); other published algorithms were used to identify hyperlipidemia, ${ }^{25}$ chronic kidney disease, ${ }^{26}$ eye disease, ${ }^{27}$ congestive heart failure, ${ }^{25}$ peripheral vascular disease, ${ }^{27}$ and dementia. ${ }^{28}$ Due to low prevalence, comorbidities were categorized into the following categories for analysis: microvascular disease (chronic kidney disease and/or eye disease), noncardiac cerebrovascular complications (stroke/transient ischemic attack and/or other neurologic conditions), ischemic heart disease/congestive heart failure (congestive heart failure and/or ischemic heart disease), and other comorbidities (dementia, collagen vascular disease, and/or malignancy).

The number of primary care, specialty, and urgent care visits were assessed at the baseline time point. Primary care visits included Family Medicine/Family Practice, Internal Medicine, Obstetrics/Gynecology, and Pediatrics/Adolescent Medicine physicians (faculty, residents, fellows), nurse practitioners, or physician assistants. ${ }^{29,30}$ Patients were assigned a primary care provider based on patterns of outpatient face-to-face Evaluation \& Management visits to physicians in the group as reported in the electronic health record billing records. ${ }^{6}$ Providers' specialties, ages, and genders were acquired from the provider group's human resources office and/or the American Medical Association 2011 Masterfile data.
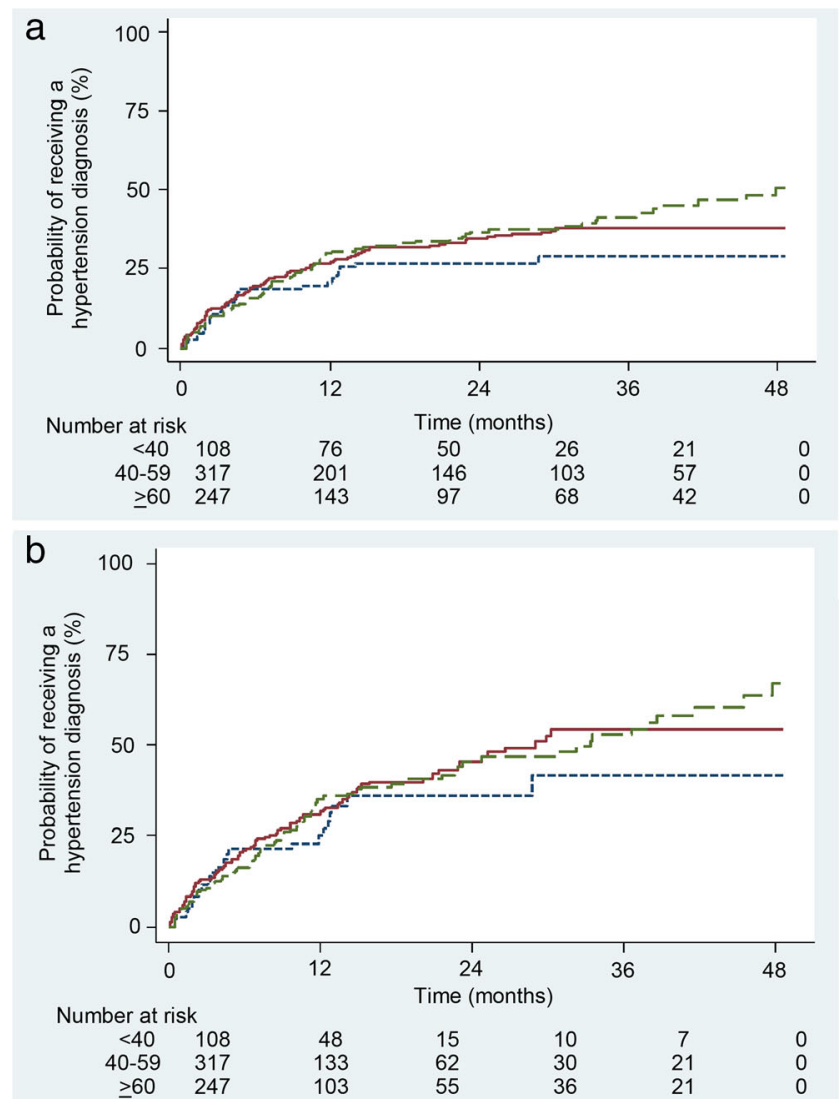

Figure 2 a Kaplan-Meier curve of time to hypertension diagnosis among patients with diabetes and incident hypertension $(\geq 130 / 80 \mathrm{mmHg})$

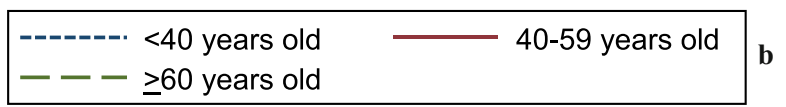

Kaplan-Meier curve of time to hypertension diagnosis among patients with diabetes and incident hypertension $(\geq 140 / 90 \mathrm{mmHg})$

\begin{tabular}{|c|c|}
\hline $\begin{array}{l}-----\cdot<40 \text { years old } \\
---\geq 60 \text { years old }\end{array}$ & $40-59$ years old \\
\hline
\end{tabular}




\section{Statistical Analysis}

The data set was constructed using SAS 9.1.3 (SAS Institute, Inc., Cary, NC) and subsequently analyzed using Stata 13.1 (Stata-Corp, College Station, TX). Initial analyses summarized categorical variables as percentages and continuous variables using means and standard deviations. Kaplan-Meier survival curves evaluated the probability of obtaining a diagnosis and receiving treatment as a function of time since meeting enrollment criteria. Multivariate Cox proportional-hazards regression analyses were conducted using shared frailty models to incorporate a random effect for each physician and account for withinphysician correlation. ${ }^{31,32}$ Adjusted hazard ratios and $95 \%$ confidence intervals were obtained for receiving an initial hypertension diagnosis and hypertension treatment. Differences were considered significant at $p<0.05$.

\section{Sensitivity Analysis}

A sensitivity analysis was conducted to account for the potential influence of lifestyle counseling prior to a hypertension diagnosis or antihypertensive medication. Cox proportionalhazards models were performed with combined outcome variables that included patients whose blood pressure normalized prior to receiving a hypertension diagnosis or antihypertensive medication.

\section{RESULTS}

\section{Descriptive Data}

A total of 771 patients met inclusion criteria (Fig. 1). There were a total of 396 providers (15 nurse practitioners and 381 physicians). Table 1 summarizes patient demographic, comorbidity, visits, and healthcare provider characteristics. Patients had a mean (standard deviation) of 15 (13) months of follow-up. Overall, $49 \%$ of patients were male, $14 \%$ had a history of Medicaid, $69 \%$ were obese, and $83 \%$ had stage 1 hypertension. ${ }^{3}$ Many chronic conditions, including dyslipidemia, atrial fibrillation, and ischemic heart disease/congestive heart failure, were more common in $\geq 60$-year olds than in younger age groups.

\section{Incident Hypertension Diagnosis Rates}

Using the 130/80 $\mathrm{mmHg}$ diagnosis threshold, 315 (41\%) of patients with diabetes and incident hypertension received a hypertension diagnosis (Fig. 2a). Adults $<40$ years old had the lowest (33\%) diagnosis rate, compared to $41 \%$ of those $40-59$ years old and $44 \%$ of those $\geq 60$ years old. Rates of diagnosis were highest during the initial 6 months after meeting hypertension criteria. Among those who received a diagnosis, the median (interquartile range) time to diagnosis was 1.9

Table 2 Adjusted HRs and $95 \%$ CIs of Independent Associations of an Initial Hypertension Diagnosis ( $\geq 130 / 80$ mmHg) and Antihypertensive Medication Initiation Among Individuals with Diabetes $(n=771)$

\begin{tabular}{|c|c|c|c|c|}
\hline \multicolumn{5}{|l|}{ Patient characteristics } \\
\hline & \multicolumn{2}{|l|}{ Diagnosis } & \multicolumn{2}{|l|}{ Treatment } \\
\hline & Adjusted HR (95 \% CI) & $p$ value & Adjusted HR (95\% CI) & $p$ value \\
\hline \multicolumn{5}{|l|}{ Age } \\
\hline Age $<40$ years & - & & - & \\
\hline Age $40-59$ years & $1.38(0.89-2.15)$ & 0.15 & $1.37(0.89-2.11)$ & 0.15 \\
\hline Age $\geq 60$ years & $1.58(0.98-2.55)$ & 0.06 & $1.32(0.83-2.10)$ & 0.25 \\
\hline Male & $0.92(0.69-1.22)$ & 0.56 & $1.28(0.97-1.68)$ & 0.08 \\
\hline \multicolumn{5}{|l|}{ Race/ethnicity } \\
\hline White & - & & - & \\
\hline Non-white $^{*}$ & $1.19(0.81-1.75)$ & 0.38 & $1.17(0.80-1.70)$ & 0.42 \\
\hline \multicolumn{5}{|l|}{ Tobacco use category } \\
\hline Current tobacco use & - & & - & \\
\hline Non-smoker/former tobacco use & $1.07(0.75-1.54)$ & 0.70 & $1.11(0.79-1.56)$ & 0.53 \\
\hline Medicaid, ever ${ }^{\dagger}$ & $1.35(0.90-2.03)$ & 0.15 & $1.29(0.86-1.93)$ & 0.21 \\
\hline Stage 2 hypertension & $1.25(0.88-1.79)$ & 0.22 & $1.19(0.85-1.68)$ & 0.31 \\
\hline \multicolumn{5}{|l|}{ Comorbidities } \\
\hline Microvascular complications of diabetes ${ }^{\S}$ & $1.12(0.66-1.89)$ & 0.68 & $0.97(0.57-1.66)$ & 0.91 \\
\hline Baseline dyslipidemia & $0.92(0.69-1.22)$ & 0.55 & $0.99(0.76-1.30)$ & 0.94 \\
\hline Atrial fibrillation & $2.18(1.21-4.67)$ & 0.03 & $3.07(1.39-6.74)$ & 0.005 \\
\hline Peripheral vascular disease & $0.18(0.04-0.74)$ & 0.02 & $0.16(0.04-0.64)$ & 0.01 \\
\hline Ischemic heart disease $\mathrm{I}^{\|}$ & $1.30(0.68-2.48)$ & 0.42 & $2.16(1.24-3.76)$ & 0.007 \\
\hline Low prevalence Indicator & $0.79(0.43-1.45)$ & 0.45 & $1.37(0.82-2.30)$ & 0.23 \\
\hline \multicolumn{5}{|l|}{ Baseline ambulatory visit counts, annual } \\
\hline Primary care visits & $0.93(0.88-0.98)$ & 0.01 & $0.93(0.88-0.98)$ & 0.01 \\
\hline \multicolumn{5}{|c|}{ 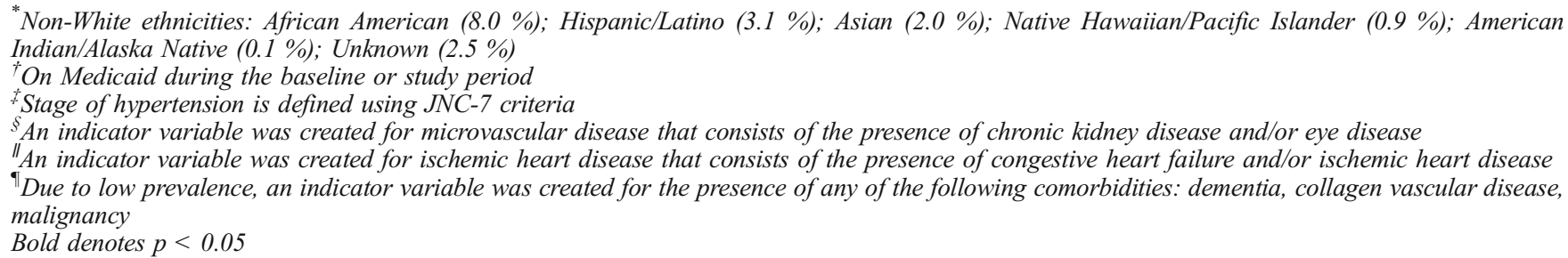 } \\
\hline
\end{tabular}


(0-8.5) months and mean (standard deviation) time to diagnosis was 5.8 (8.8) months. Using the 140/90 $\mathrm{mmHg}$ diagnosis threshold (Fig. 2b), 398 (52\%) of patients received a hypertension diagnosis and the differences in diagnosis rates were similar across age groups.

\section{Associations with an Initial Hypertension Diagnosis}

After adjusting for patient and provider factors, using the 130/ $80 \mathrm{mmHg}$ diagnosis threshold (Table 2), age was not associated with hypertension diagnosis rates. A baseline diagnosis of atrial fibrillation (HR 2.18; 1.21-4.67) was associated with a faster diagnosis rate. Slower diagnosis rates were associated with peripheral vascular disease (HR 0.18; 0.04-0.74) and fewer primary care visits (HR 0.93; 0.88-0.98). For $140 / 90 \mathrm{mmHg}$ (Table 3), similarly, peripheral vascular disease was associated with a slower diagnosis. However, Medicaid use was associated with a faster diagnosis rate (HR 1.62; 1.07-2.45). Provider characteristics were not associated with an initial hypertension diagnosis for $130 / 80 \mathrm{mmHg}$ or $140 / 90 \mathrm{mmHg}$.

\section{Antihypertensive Medication Initiation Rates}

For 130/80 $\mathrm{mmHg}$, an initial antihypertensive medication was prescribed in 286 (37 \%) patients (Fig. 3a).
Adults $<40$ years of age had the lowest rate of antihypertensive medication initiation (31\%), compared to $37 \%$ of $40-59$-year olds and $40 \%$ of $\geq 60$-year olds. Rates of medication initiation were highest in the initial 6 months. Among patients who received an antihypertensive medication, the median (interquartile range) time to treatment was $3.3(0.2-10.0)$ months and the mean (standard deviation) time to treatment was 6.9 (9.0) months. Using the $140 / 90 \mathrm{mmHg}$ threshold (Fig. 3b), 377 (49\%) received antihypertensive medication and < 40-year olds continued to have the slowest medication initiation rate.

\section{Associations with Time to Antihypertensive Medication Initiation}

Using the cut-point of 130/80 mmHg (Table 2), factors associated with faster medication initiation included atrial fibrillation (HR 3.07; 1.39-6.74) and ischemic heart disease/ congestive heart failure (HR 2.16; 1.24-3.76). Patients with peripheral vascular disease (HR 0.16;0.04-0.64) and fewer primary care visits (HR $0.93 ; 0.88-0.98$ ) had significantly slower medication initiation rates. While not statistically significant, a trend suggests that those $\geq 60$ years of age may have received antihypertensive medication at a faster rate than

Table 3 Adjusted HRs and $95 \%$ CIs of Independent Associations of an Initial Hypertension Diagnosis ( $\geq 140 / 90$ mmHg) and Antihypertensive Medication Initiation Among Individuals with Diabetes $(n=771)$

\begin{tabular}{|c|c|c|c|c|}
\hline \multicolumn{5}{|l|}{ Patient characteristics } \\
\hline & \multicolumn{2}{|l|}{ Diagnosis } & \multicolumn{2}{|l|}{ Treatment } \\
\hline & Adjusted HR (95\% CI) & $P$ value & Adjusted HR (95\% CI) & $p$ value \\
\hline \multicolumn{5}{|l|}{ Age } \\
\hline Age $<40$ years & - & & - & \\
\hline Age $40-59$ years & $1.35(0.86-2.11)$ & 0.19 & $1.22(0.79-1.89)$ & 0.38 \\
\hline Age $\geq 60$ years & $1.42(0.87-2.32)$ & 0.16 & $1.08(0.67-1.74)$ & 0.77 \\
\hline Male & $0.82(0.62-1.09)$ & 0.17 & $1.10(0.84-1.46)$ & 0.49 \\
\hline \multicolumn{5}{|l|}{ Race/ethnicity } \\
\hline White & - & & - & \\
\hline Non-white* & $1.28(0.87-1.90)$ & 0.21 & $1.27(0.86-1.88)$ & 0.22 \\
\hline \multicolumn{5}{|l|}{ Tobacco use } \\
\hline Current tobacco use & - & & - & \\
\hline Non-smoker/former tobacco use & $1.04(0.72-1.51)$ & 0.82 & $1.16(0.82-1.65)$ & 0.40 \\
\hline Medicaid, ever ${ }^{\dagger}$ & $1.62(1.07-2.45)$ & 0.02 & $1.43(0.94-2.16)$ & 0.10 \\
\hline Stage 2 hypertension & $1.15(0.80-1.66)$ & 0.44 & $0.98(0.68-1.40)$ & 0.91 \\
\hline \multicolumn{5}{|l|}{ Comorbidities } \\
\hline Microvascular complications of diabetes ${ }^{\S}$ & $1.26(0.74-2.15)$ & 0.39 & $0.94(0.54-1.63)$ & 0.82 \\
\hline Baseline dyslipidemia & $1.01(0.76-1.34)$ & 0.96 & $1.10(0.83-1.45)$ & 0.52 \\
\hline Atrial fibrillation & $2.22(0.85-5.85)$ & 0.11 & $2.86(1.26-6.48)$ & 0.01 \\
\hline Peripheral vascular disease & $0.23(0.06-0.95)$ & 0.04 & $0.19(0.05-0.79)$ & 0.02 \\
\hline Ischemic heart disease" & $1.48(0.76-2.87)$ & 0.25 & $2.77(1.52-5.05)$ & 0.001 \\
\hline Low prevalence indicator & $0.79(0.42-1.47)$ & 0.46 & $1.38(0.81-2.34)$ & 0.23 \\
\hline \multicolumn{5}{|l|}{ Baseline ambulatory visit counts, annual } \\
\hline Primary care visits & $0.99(0.94-1.05)$ & 0.81 & $0.99(0.94-1.04)$ & 0.73 \\
\hline \multicolumn{5}{|c|}{$\begin{array}{l}\text { "Non-White ethnicities: African American (8.0\%); Hispanic/Latino (3.1\%); Asian (2.0\%); Native Hawaiian/Pacific Islander (0.9\%); American } \\
\text { Indian/Alaska Native (0.1\%); Unknown (2.5\%) } \\
\text { "On Medicaid during the baseline or study period } \\
{ }^{\circ} \text { Stage of hypertension is defined using JNC-7 criteria } \\
\text { SAn indicator variable was created for microvascular disease that consists of the presence of chronic kidney disease and/or eye disease } \\
\text { "An indicator variable was created for ischemic heart disease that consists of the presence of congestive heart failure and/or ischemic heart disease } \\
\text { "Due to low prevalence, an indicator variable was created for the presence of any of the following comorbidities: dementia, collagen vascular disease, } \\
\text { malignancy } \\
\text { Bold denotes } p<0.05\end{array}$} \\
\hline
\end{tabular}



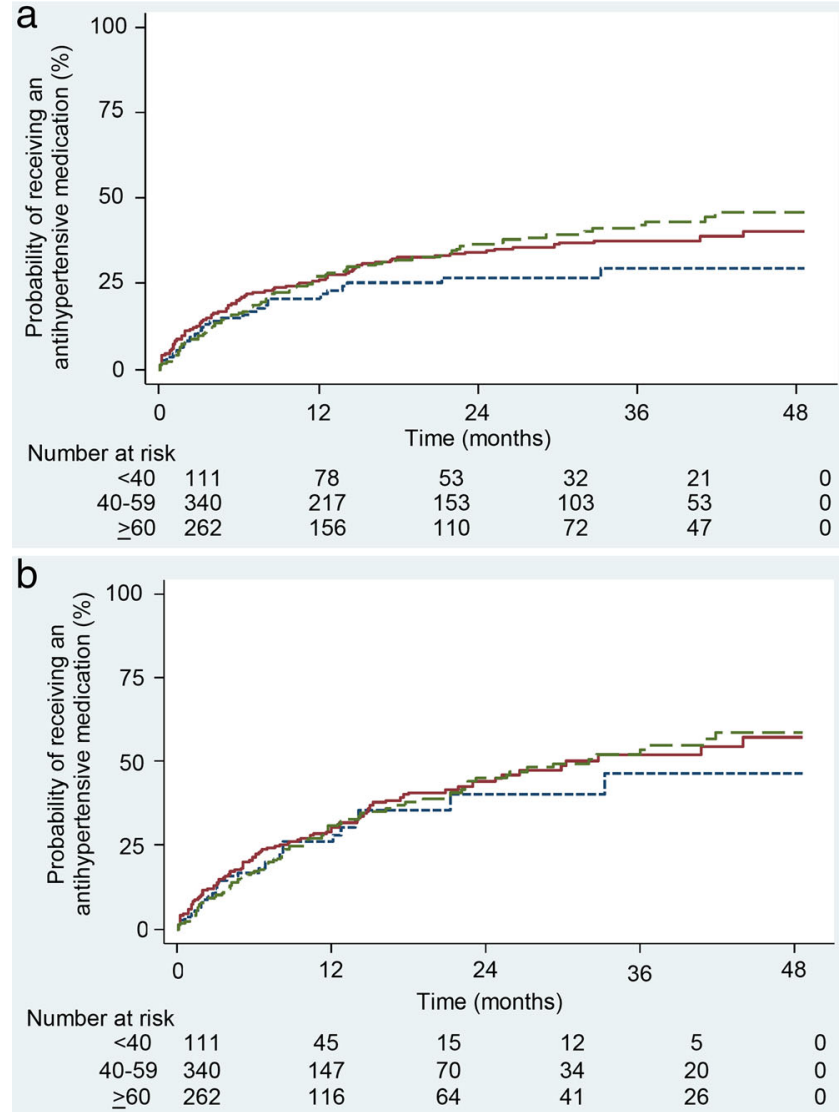

Figure 3 a Kaplan-Meier curve of time to antihypertensive medication initiation among patients with diabetes and incident hypertension $(\geq 130 / 80 \mathrm{mmHg})$

$$
\begin{array}{ll}
-----\cdot<40 \text { years old } & 40-59 \text { years old } \\
---\geq 60 \text { years old } &
\end{array}
$$

b Kaplan-Meier curve of time to antihypertensive medication initiation among patients with diabetes and incident hypertension $(\geq 140 / 90 \mathrm{mmHg}$ )

$\begin{array}{ll}--\cdot--\cdot<40 \text { years old } & <40-59 \text { years old } \\ ---\geq 60 \text { years old } & \end{array}$

adults $<40$ years of age. Similarly, for $140 / 90 \mathrm{mmHg}$ (Table 3), atrial fibrillation and ischemic heart disease were associated with faster medication initiation rates; peripheral vascular disease was associated with slower rates. Provider characteristics were not associated with antihypertensive medication initiation for $130 / 80 \mathrm{mmHg}$ or $140 / 90 \mathrm{mmHg}$.

\section{Sensitivity Analysis}

Cox proportional-hazards models were performed with combined outcome variables that included patients whose blood pressure normalized prior to receiving a hypertension diagnosis or antihypertensive medication. Overall, the, associations remained consistent with the initial models. Using the cutpoint of $130 / 80 \mathrm{mmHg}$, peripheral vascular disease (HR 0.28;
$0.10-0.76$ ) was associated with slower hypertension diagnosis rates. Atrial fibrillation (HR 2.7; 1.3-5.6) and ischemic heart disease/congestive heart failure (HR 2.2; 1.3-3.6) were associated with faster medication initiation; peripheral vascular disease (HR 0.31;0.14-0.82) was associated with slower medication initiation. Findings were similar for 140/ $90 \mathrm{mmHg}$.

\section{DISCUSSION}

In a cohort of patients seen in a single health system, we observed that delays in time to diagnosis and treatment of hypertension were common among patients with diabetes. Even with the higher cut-point $(140 / 90 \mathrm{mmHg}$ ), approximately $50 \%$ of patients with diabetes mellitus remained undiagnosed and untreated for hypertension. Our seminal findings highlight important associations contributing to clinical inertia (delays) in the hypertension management of patients with diabetes. ${ }^{18-20}$

Prior literature supports our main findings. A study in Spain evaluated delays in hypertension diagnosis among patients with diabetes mellitus. ${ }^{3}$ Although generalizability to a U.S. population is limited due to healthcare system differences, similarly, patient-level factors (comorbidities) were the primary associations with hypertension diagnosis and treatment rates. In addition, several studies described delays in hypertension diagnosis and treatment in a U.S. population not limited to patients with diabetes. ${ }^{10,33-35}$ Similar to those studies, we demonstrated that fewer primary care visits in the baseline period were associated with slower diagnosis and treatment rates, emphasizing the importance of timely hypertension follow-up.

Unfortunately, among patients with diabetes, comorbid conditions can negatively impact patient care, given the competing demands, and they contribute to clinical inertia in hypertension management. ${ }^{18-20}$ Conditions with similar pathophysiology and treatments (concordant conditions) may cue providers to offer synergistic care for the conditions with overlapping care goals. ${ }^{36,37}$ This may explain improved hypertension diagnosis and treatment rates in our study for patients with diabetes and atrial fibrillation or ischemic heart disease/congestive heart failure. In contrast, discordant conditions may promote clinical inertia; however, there is conflicting data. In one study, patients were less likely to have antihypertensive treatment intensified for uncontrolled hypertension with each additional discordant condition. ${ }^{38}$ In another study, patients with higher clinical complexity, including discordant conditions, were more likely to receive higher quality diabetes care and achieve hypertension control. ${ }^{39}$ In our study, peripheral vascular disease, a presumably concordant condition, was associated with decreased rates of hypertension diagnosis and treatment. Significantly increased mortality associated with advanced peripheral vascular disease may explain these findings, since guideline-concordant care may not 
have the same benefit-to-risk ratio in patients with advanced comorbidities. ${ }^{39}$

Given the management complexity of diabetes with other comorbid conditions, our data further supports the idea that future interventions should consider patients with comorbidities as a target group. Guidelines recommend a team-based approach to diabetes management, ${ }^{1}$ to address complex comorbidities and increase the achievement of diabetes-related treatment goals. ${ }^{40,41}$ However, tailored strategies such as clinical decision support are needed to assist providers and patients with complex comorbidity management. ${ }^{42}$

One of the limitations of this study is the use of data from a single healthcare system, potentially limiting the generalizability. However, this healthcare system is one of the ten largest physician practices in the United States, with primary care clinics in both urban and rural settings. Misclassification of hypertension or other comorbidities is a concern; however, the use of established algorithms decreases this risk. Diabetes screening was based on established guidelines at the time of the study. Our study addressed prevalent diabetes; therefore, we did not assess time from a diabetes diagnosis. However, the length of follow-up should reflect hypertension management in this population. Our exclusion criteria (previous antihypertensive medication) decreased the prevalence of atrial fibrillation and congestive heart failure compared to previous observational studies. ${ }^{43,44} \mathrm{Al}$ though this may limit the generalizability, our rates reflect a population of patients with diabetes and incident hypertension, and highlight the importance of a timely response to newly elevated blood pressures. Occasionally, patients are started on antihypertensive medication (e.g., ACE-inhibitor) due to a diagnosis of diabetes and not hypertension. However, in our analysis, only $9.3 \%$ of patients received an antihypertensive medication without a diagnosis of hypertension. Additionally, patients were censored if blood pressures normalized prior to a hypertension diagnosis or antihypertensive initiation. Therefore, patients only accrued time if they had continuously elevated blood pressures. Lastly, some patients may have been initially treated with lifestyle modifications resulting in blood pressure normalization. To address this concern, sensitivity analyses were performed and demonstrated similar results to our initial models: complex comorbidities and visit frequency remained important associations with hypertension diagnosis and treatment. Unfortunately, ambulatory blood pressure data was not available; future studies would be beneficial to evaluate for white coat and masked hypertension in this population.

In conclusion, at the $130 / 80 \mathrm{mmHg}$ threshold, the majority of patients with diabetes and incident hypertension remained undiagnosed (59\%) and untreated (63\%) for hypertension. Analysis at $140 / 90 \mathrm{mmHg}$ demonstrated that approximately $50 \%$ of patients remained undiagnosed and untreated.
Interventions targeting complex patients with multiple comorbidities are needed to improve hypertension diagnosis and treatment rates in patients with diabetes.

Acknowledgements: Contributors: The authors gratefully acknowledge Katie Ronk, BS, for data preparation, and Jamie LaMantia, BS, and Colleen Brown, BA, for manuscript preparation.

Funders: Research reported in this manuscript was supported by the UW Health Innovation Program and the Clinical and Translational Science Award (CTSA) program, previously through the National Center for Research Resources (NCRR) under award number UL1RR025011, and now by the National Center for Advancing Translational Sciences (NCATS) of the National Institutes of Health under award number U54TROOOO21. Margaret Wallace and Elizabeth Magnan are supported by a National Research Service Award (T32HP10010) from the Health Resources and Services Administration to the University of Wisconsin Department of Family Medicine. Heather Johnson is supported by the National Heart, Lung, and Blood Institute of the National Institutes of Health under award number K23HL112907, and also by the University of Wisconsin Centennial Scholars Program of the University of Wisconsin School of Medicine and Public Health. The content is solely the responsibility of the authors and does not necessarily represent the official views of the National Institutes of Health.

Additional funding for this project was provided by the University of Wisconsin School of Medicine and Public Health from The Wisconsin Partnership Program.

Prior Presentations: Some of the findings reported in the study were presented by Margaret Wallace in abstract form at the 2013 Wisconsin Health Improvement and Research Partnership Forum on 12 September 2013.

Conflicts of Interest: E. Magnan and H. Johnson have clinical appointments with the academic group practice that has a financial interest in delivering care to the general population from which study subjects were drawn. For the remaining authors, no conflicts were declared.

Corresponding Author: Heather M. Johnson, MD MS; Division of Cardiovascular Medicine, H4/512 CSC, MC 3248, 600 Highland Avenue, Madison, WI 53792, USA (e-mail: hm2@medicine.wisc.edu).

\section{REFERENCES}

1. American Diabetes Association. Standards of medical care in diabetes2014. Diabetes Care. 2014;37(1):S14-80.

2. Parati G, Bilo G, Ochoa JE. Benefits of tight blood pressure control in diabetic patients with hypertension: importance of early and sustained implementation of effective treatment strategies. Diabetes Care. 2011;34 (2):S297-303.

3. de Burgos-Lunar C, Del Cura-González I, Salinero-Fort MA, GómezCampelo P, Pérez de Isla L, Jiménez-Garcia R. Delayed diagnosis of hypertension in diabetic patients monitored in primary care. Rev Esp Cardiol. 2013;66:700-6.

4. Hatahet MA, Bowhan J, Clough EA. Wisconsin Collaborative for Healthcare Quality (WCHQ): lessons learned. WMJ. 2004;103:45-8.

5. Sheehy A, Pandhi N, Coursin DB, et al. Minority status and diabetes screening in an ambulatory population. Diabetes Care. 2011;34:1289-94.

6. Thorpe CT, Flood GE, Kraft SA, Everett CM, Smith MA. Effect of patient selection method on provider group performance estimates. Med Care. 2011;49:780-5.

7. Chobanian AV, Bakris GL, Black HR, et al. The Seventh Report of the Joint National Committee on Prevention, Detection, Evaluation, and Treatment of High Blood Pressure: the JNC 7 report. JAMA. 2003;289:2560-72.

8. Myers MG, Tobe Sw, McKay DW, et al. New algorithm for the diagnosis of hypertension. Am J Hypertens. 2005; 18:1369-74.

9. Schmittdiel J, Selby JV, Swain B, et al. Missed opportunities in cardiovascular disease prevention?: low rates of hypertension recognition for women at medicine and obstetrics-gynecology clinics. Hypertension. 2011;57:717-22. 
10. Johnson HM, Thorpe CT, Bartels CM, et al. Undiagnosed hypertension among young adults with regular primary care use. J Hypertens. 2014;32:65-74.

11. Hebert PL, Geiss LS, Tierney EF, Engelgau MM, Yawn BP, McBean AM. Identifying persons with diabetes using Medicare claims data. Am J Med Qual. 1999; 14:270-7.

12. Sheehy AM, Flood GE, Tuan WJ, Liou JI, Coursin DB, Smith MA. Analysis of guidelines for screening diabetes mellitus in an ambulatory population. Mayo Clin Proc. 2010;85:27-35.

13. Tu K, Chen Z, Lipscombe LL, Canadian Hypertension Education Program Outcomes Research Taskforce. Prevalence and incidence of hypertension from 1995 to 2005: a population-based study. CMAJ. 2008;178:1429-35.

14. Manson JM, McFarland B, Weiss S. Use of an automated database to evaluate markers for early detection of pregnancy. Am J Epidemiol. 2001;154:180-7.

15. Cushman WC, Evans GW, Byington RP, et al. Effects of intensive bloodpressure control in type 2 diabetes mellitus. $N$ Engl $\mathrm{J}$ Med. 2010;362:1575-85.

16. James PA, Oparil S, Carter BL, et al. 2014 evidence-based guideline for the management of high blood pressure in adults: report from the panel members appointed to the Eighth Joint National Committee (JNC 8). JAMA. 2014;311:507-20.

17. Hansen ML, Gunn PW, Kaelber DC. Underdiagnosis of hypertension in children and adolescents. JAMA. 2007;298:874-9.

18. Parchman ML, Pugh JA, Romero RL, Bowers KW. Competing demands or clinical inertia: the case of elevated glycosylated hemoglobin. Ann Fam Med. 2007;5: 196-201.

19. O'Connor PJ, Sperl-Hillen JM, Johnson PE, Rush WA, Blitz G. Clinical Inertia and Outpatient Medical Errors. In: Henriksen K, Battles JB, Marks ES, Lewin DI, eds. Advances in Patient Safety: From Research to Implementation (Volume 2: Concepts and Methodology). Rockville: Agency of Healthcare Research and Quality (US); 2005:293-308.

20. Huebschmann AG, Mizrahi T, Soenksen A, Beaty BL, Denberg TD. Reducing clinical inertia in hypertension treatment: a pragmatic randomized controlled trial. J Clin Hypertens (Greenwich). 2012;14:322-9.

21. Gil-Guillén V, Orozco-Beltrán D, Peréz RP, et al. Clinical inertia in diagnosis and treatment of hypertension in primary care: quantification and associated factors. Blood Press. 2010;19:3-10.

22. Buccaneer Computer Systems \& Services, Inc. Chronic Condition Data Warehouse Reference List. Available at: www.ccwdata.org/web/guest/ condition-categories. Accessed January 12, 2015.

23. Goldstein LB. Accuracy of ICD-9-CM coding for the identification of patients with acute ischemic stroke: effect of modifier codes. Stroke. 1998;29:1602-4.

24. Elixhauser A, Steiner C, Harris DR, Coffey RM. Comorbidity measures for use with administrative data. Med Care. 1998;36:8-27.

25. Borzecki AM, Wong AT, Hickey EC, Ash AS, Berlowitz DR. Identifying hypertension-related comorbidities from administrative data: what's the optimal approach? Am J Med Qual. 2004;19:201-6.

26. Foley RN, Murray AM, Li S, et al. Chronic kidney disease and the risk for cardiovascular disease, renal replacement, and death in the
United States Medicare population, 1998 to 1999. J Am Soc Nephrol. 2005; 16:489-95.

27. Newton KM, Wagner EH, Ramsey SD, et al. The use of automated data to identify complications and comorbidities of diabetes: a validation study. J Clin Epidemiol. 1999;52:199-207.

28. Taylor DH Jr, Ostbye T, Langa KM, Weir D, Plassman BL. The accuracy of Medicare claims as an epidemiological tool: the case of dementia revisited. J Alzheimers Dis. 2009;17:807-15.

29. Druss BG, Marcus SC, Olfson M, Tanielian T, Pincus HA. Trends in care by nonphysician clinicians in the United States. N Engl J Med. 2003;348:130-7.

30. Pham HH, Schrag $\mathbf{D}$, Hargraves $\mathbf{J}$, Bach PB. Delivery of preventive services to older adults by primary care physicians. JAMA. 2005;294:473-81.

31. Gutierrez RG, StataCorp. Parametric frailty and shared frailty survival models. The Stata Journal. 2002;2:22-44.

32. McGilchrist CA, Aisbett CW. Regression with frailty in survival analysis. Biometrics. 1991;47:461-6.

33. Brooks EL, Preis SR, Hwang SJ, et al. Health insurance and cardiovascular disease risk factors. Am Med J. 2010;123:741-7.

34. Johnson HM, Thorpe CT, Bartels CM, et al. Antihypertensive medication initiation among young adults with regular primary care use. J Gen Intern Med. 2014;29:723-31.

35. Nguyen GC, Waddell EN, Thomas JC, Huston SL, Kerker BD, Gwynn RC. Awareness, treatment, and control of hypertension and hypercholesterolemia among insured residents of New York City, 2004. Prev Chronic Dis. 2011;8:A109.

36. Pentakota SR, Rajan M, Fincke BG, et al. Does diabetes care differ by type of chronic comorbidity?: An evaluation of the Piette and Kerr framework. Diabetes Care. 2012;35:1285-92.

37. Piette JD, Kerr EA. The impact of comorbid chronic conditions on diabetes care. Diabetes Care. 2006;29:725-31.

38. Turner BJ, Hollenbeak CS, Weiner M, Ten Have T, Tang SS. Effect of unrelated comorbid conditions on hypertension management. Ann Intern Med. 2008; 148:578-86.

39. Woodard LD, Urech T, Landrum CR, Wang D, Petersen LA. Impact of comorbidity type on measures of quality for diabetes care. Med Care. 2011;49:605-10.

40. Leal S, Glover JJ, Herrier RN, Felix A. Improving quality of care in diabetes through a comprehensive pharmacist-based disease management program. Diabetes Care. 2004;27:2983-4.

41. Machado M, Bajcar J, Guzzo GC, Einarson TR. Sensitivity of patient outcomes to pharmacist interventions. Part I: systematic review and metaanalysis in diabetes management. Ann Pharmacother. 2007;41:1569-82.

42. Vogeli C, Shields AE, Lee TA, et al. Multiple chronic conditions: prevalence, health consequences, and implications for quality, care management, and costs. J Gen Intern Med. 2007;22(3):391-5.

43. Nichols GA, Hillier TA, Erbey JR, Brown JB. Congestive heart failure in type 2 diabetes: prevalence, incidence, and risk factors. Diabetes Care. 2001;24:1614-9.

44. Nichols GA, Reinier K, Chugh SS. Independent contribution of diabetes to increased prevalence and incidence of atrial fibrillation. Diabetes Care. 2009;32:1851-6. 